

\title{
PROCESSES MEDIATED BY GOLD NANOPARTICLES ENCAPSULATED IN POLYMERIC GELS EVIDENCED BY EPR SPECTROSCOPY
}

\author{
Iulia MATEI, Marioara BEM, Anca Ruxandra LEONTIEŞ, Cristina RĂDUȚIU, Elena Irina POPESCU, \\ Sorin MOCANU, Florența SAVONEA, Rodica BĂRĂȚOIU and Gabriela IONIȚA $\breve{A}^{*}$
}

Roumanian Academy, Institute of Physical Chemistry "Ilie Murgulescu”, Splaiul Independentei 202, Bucharest, 060021, Roumania

Received October 28, 2020

Gold $\left(\mathrm{Au}^{0}\right)$ nanoparticles (AuNPs) have been investigated for decades as selective catalysts for a series of reactions including alcohol oxidation, alkene hydrogenation and nucleophilic addition to $\mathrm{C}-\mathrm{C}$ multiple bonds. In this study, the reduction/oxidation processes mediated by AuNPs embedded within a polymeric hydrogel have been tested. In particular, we monitored two processes: i) the reduction of 4-nitrophenol and ii) the reduction of a TEMPO moiety covalently linked to a fluorescent moiety, in the presence of AuNPs/hydrogel. The hybrid AuNPs/hydrogel material was obtained by reduction of a gold salt within the cross-linked poly(ethylene glycol)/ $\beta$-cyclodextrin gel following a procedure previously reported. We found that this material is suitable for cyclic reduction of 4-nitrophenol as the material is not structurally modified after the reduction process. The electron paramagnetic resonance (EPR) signal of the TEMPO moiety decreases in the first instance, due to reduction by AuNPs, and slightly increases in time, proving the oxidizing property of AuNPs embedded in hydrogel.

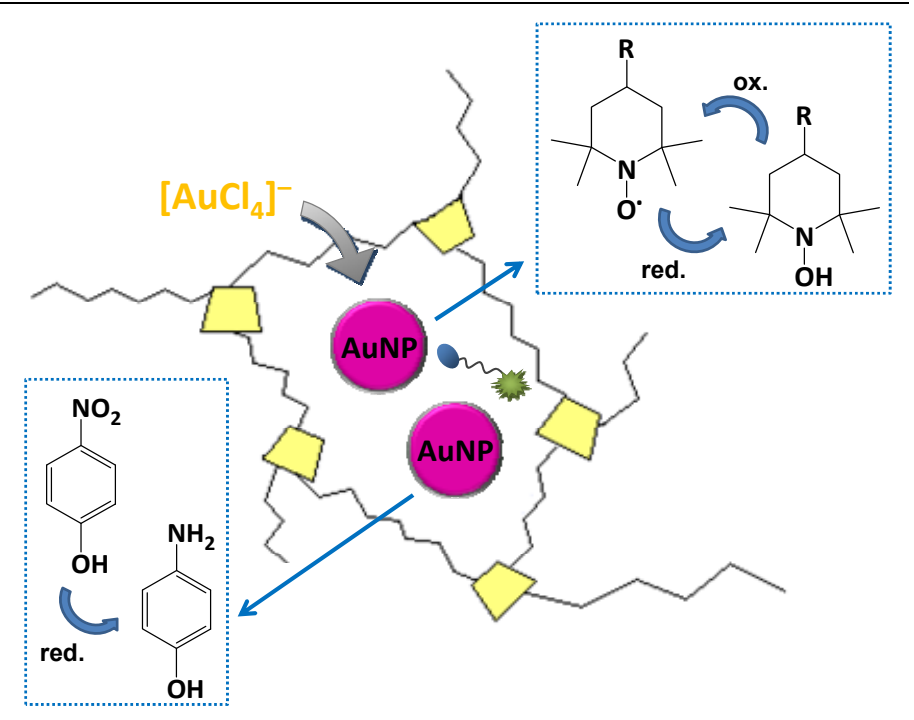

\section{INTRODUCTION}

Catalytic properties of gold, observed exclusively for gold nanoparticles (AuNPs), have gained an increasing interest during the last decades. ${ }^{1,2}$ The catalytic activity of supported and unsupported AuNPs has been studied in order to gain information on mechanistic aspects, or to control parameters such as particle composition, stability, size and shape, which play key roles in particular systems. ${ }^{1-3}$ The stability of AuNPs in solution is commonly ensured by the presence of a ligand shell of thiols, amines or triphenyl phosphine. ${ }^{4-6}$ In order to stabilize AuNPs and also to facilitate separation of reaction products and possible reuse of the catalyst, various preparation methods for AuNPs on different support materials have been described, including the in situ generation of nanoparticles by reduction of an $\mathrm{Au}(\mathrm{III})$ precursor adsorbed on the support material, and deposition-precipitation suitable for metal oxide supports. ${ }^{1,7}$ Another method involves adsorption of preformed AuNPs protected by organic layers of low molecular weight compounds

${ }^{*}$ Corresponding author: ige@icf.ro 
(thiols, amines, phosphines) or polymers (polysaccharides, dendrimers, polyethylene glycols) by metal oxides. ${ }^{1,8,9}$ In most cases, AuNPs are adsorbed to the surface of the solid support, although embedding AuNPs within metal oxide matrices like micro or mesoporous silica has been proven more efficient. $^{1,10}$

Hybrid materials like AuNPs dispersed in various gel systems represent an alternative to the materials based on solid supports. These hybrid materials are commonly investigated in connexion with their applications in catalysis and biomedical fields. Such AuNPs can be obtained in situ in the presence of different low molecular weight gelators like amines, ${ }^{11}$ thiols, ${ }^{12}$ and urea derivatives. ${ }^{13}$ The supramolecular gel/AuNPs hybrid materials often show an altered morphology of the gel network compared to the gel obtained in the absence of AuNPs. Polymeric hydrogels/AuNPs assembled through non-covalent interactions have also been reported. ${ }^{2,14}$ AuNPs were generated in situ by reduction of a gold salt precursor in the presence of a reducing agent, usually sodium borohydride.

In the particular case of a polymeric hydrogel resulted by crosslinking poly(ethylene glycol) (PEG900) units with $\beta$-cyclodextrin ( $\beta$-CD), the slow reduction of $A u(I I I)$ and the formation of AuNPs was observed in the absence of common reducing agents. ${ }^{15}$ In this case, the hydroxyl groups of the cyclodextrin units are responsible for reducing $\mathrm{Au}(\mathrm{III})$. The particle size of the obtained
AuNPs is in the range $10-50 \mathrm{~nm}^{16}$ and the nanoparticles are not released from the gel network (Fig. 1). Therefore, in this study we tested the catalytic activity of AuNPs embedded in PEG900/ $\beta$ $\mathrm{CD}$ hydrogel on the reduction/oxidation of 4nitrophenol and of the TEMPO paramagnetic moiety linked to a fluorescent pyrene moiety (Fig. 1). ${ }^{16}$

\section{RESULTS AND DISCUSSION}

\section{Characterisation of the PEG900/ $\beta$-CD hydrogel embedded with AuNPs hybrid material}

Our previous studies have shown that PEG/ $\beta$ $\mathrm{CD}$ polymeric hydrogels have the ability to encapsulate organic molecules like spin probes $^{17}$ and dual molecular probes, ${ }^{16}$ as well as inorganic salts. ${ }^{15}$ The hybrid system PEG900/ $\beta-C D / A u N P s$ has been previously reported and characterised. ${ }^{15}$ Taking into account that AuNPs do not diffuse from this hydrogel matrix, and that the AuNPs size is in the nanoscale range, we test here the catalytic properties of this hybrid material in the reduction of 4-nitrophenol. The properties of the material to encapsulate and release low molecular weight compounds combined with the physical stability of the $P E G / \beta-C D$ hydrogel/AuNPs matrix are exploited in our investigation of the processes that occur at the surface of the encapsulated AuNPs.

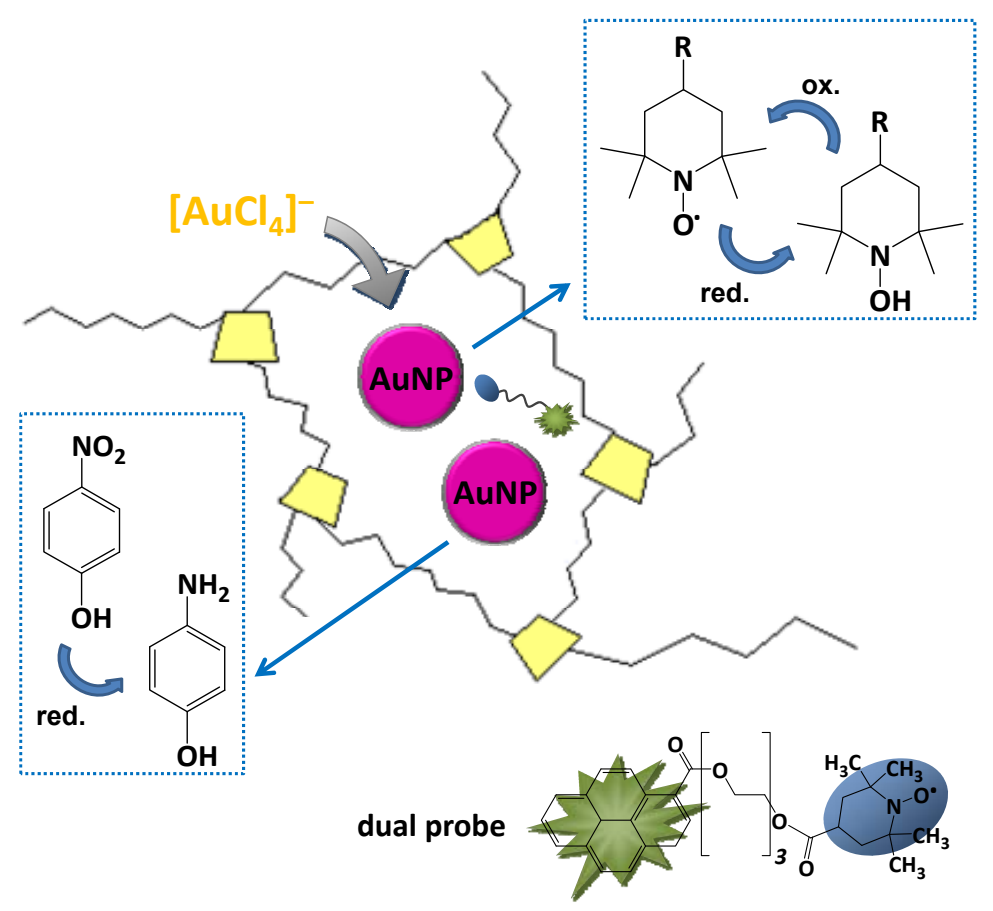

Fig. 1 - Schematic representation of the PEG900/ß-CD hydrogel/AuNPs hybrid material and molecular structure of the $\mathrm{Py}(\mathrm{EG})_{3} \mathrm{~T}$ dual probe. 
The reduction of 4-nitrophenol by sodium borohydride $\left(\mathrm{NaBH}_{4}\right)$ is a model reaction used to assess the catalytic activity of metallic nanoparticles. ${ }^{18,19}$ The PEG900/ $\beta-C D$ hydrogel/ AuNPs material is in equilibrium with the solution, which contains 4-nitrophenol (initial), 4aminophenol (after complete reduction) or a mixture of both chemical species. Thus, chemical reduction is accompanied by redistribution between hydrogel mass and solution of the species present in the system. The diffusion of 4nitrophenol within the gel, the accessibility of the reactant to the surface of encapsulated AuNPs and the diffusion of 4-aminophenol away from the AuNPs surface constitute rate-limiting steps of the process. In a similar experiment, using PEG900/ $\beta$ $\mathrm{CD}$ hydrogel and 4-nitrophenol solution, the diffusion of 4-nitrophenol in gel and the stability of the system over time were evidenced.

The reduction kinetics was monitored by recording the absorption spectra of the reaction mixture. As the reaction proceeds, the gradual decrease in intensity of the absorption band of 4nitrophenol (with a maximum at $400 \mathrm{~nm}$ ) is accompanied by the appearance and increase in intensity of the absorption band of 4-aminophenol (maximum at $310 \mathrm{~nm}$ ). In Fig. 2 are shown the absorption spectra of 4-nitrophenol at time zero and of 4-aminophenol after 4 days from the start of the reduction process. The absorbance of 4-nitrophenol decreases slowly for $120 \mathrm{~min}$ after mixing the PEG900/ $\beta-\mathrm{CD} / \mathrm{AuNPs}$ hybrid material with the 4-nitrophenol solution. We can consider this interval as an induction time prior to reduction. The time evolution of the absorbance at $400 \mathrm{~nm}$ evidences two domains with different kinetic rates. Fig. 3 shows the plots of $\ln \mathrm{A} / \mathrm{A}_{0}$ as a function of time in order to evaluate the apparent reaction rate constants $\left(\mathrm{k}_{\mathrm{I}}\right.$ and $\left.\mathrm{k}_{\mathrm{II}}\right)$ of the pseudo-first-order process of 4-nitrophenol reduction. These values are $\mathrm{k}_{\mathrm{I}}=1.43 \times 10^{-3} \mathrm{~min}^{-1}$ for the first domain and $\mathrm{k}_{\mathrm{II}}$ $=6.31 \times 10^{-4} \mathrm{~min}^{-1}$ for the second one. The reduction of 4-nitrophenol occurs with a slow rate in comparison with other systems that use AuNPs as catalytic agents. ${ }^{20,21}$ This is due to the fact that, apart from the chemical reduction process, other factors should be considered, such as the diffusion of the reactant to the catalytic $\mathrm{Au}(0)$ centres at the nanoparticle surface, the diffusion of the reaction product from the surface of AuNPs followed by its diffusion from gel to solution, and the fixed positions of AuNPs within the hydrogel matrix. The relatively large dimensions of AuNPs (10-50 $\mathrm{nm})$ also play a role. Generally, the catalytic activity of AuNPs decreases with increasing nanoparticle size, as small AuNPs exhibit an increased number of coordinatively unsaturated surface $\mathrm{Au}$ atoms and a larger ratio of surface to total $\mathrm{Au}$ atoms. ${ }^{22}$ Another factor that can contribute is the interaction of AuNPs with the amino group of 4-aminophenol, since it is known that amines have a good affinity for the AuNPs surface. ${ }^{6}$
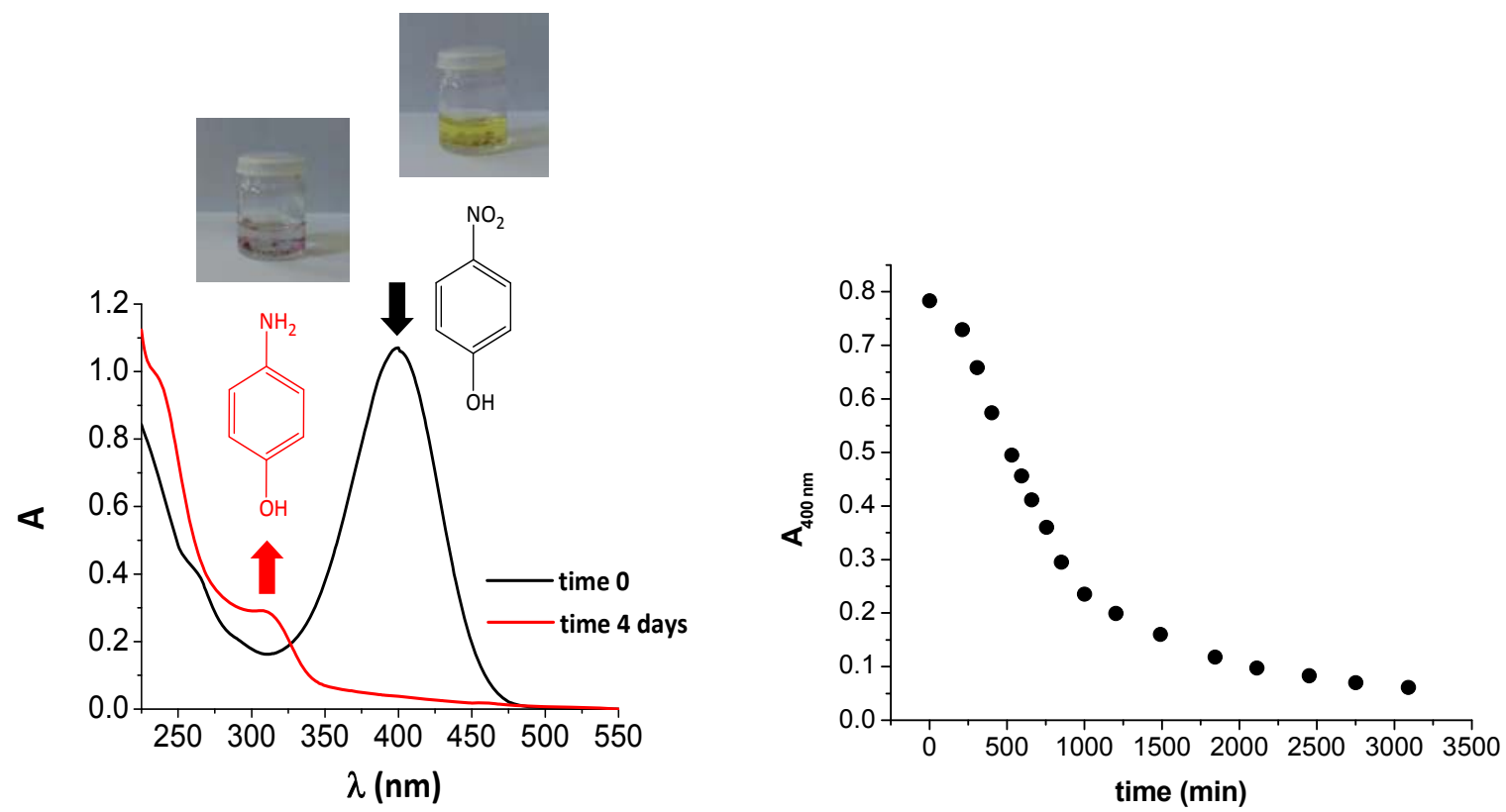

Fig. 2 - Reduction of 4-nitrophenol $\left(6 \times 10^{-5} \mathrm{M}\right.$ in $\left.0.1 \mathrm{M} \mathrm{NaOH}\right)$ to 4 -aminophenol by $\mathrm{NaBH}_{4}(0.2 \mathrm{M})$ in the presence of the PEG900/ $\beta$-CD hydrogel/AuNPs hybrid material. 

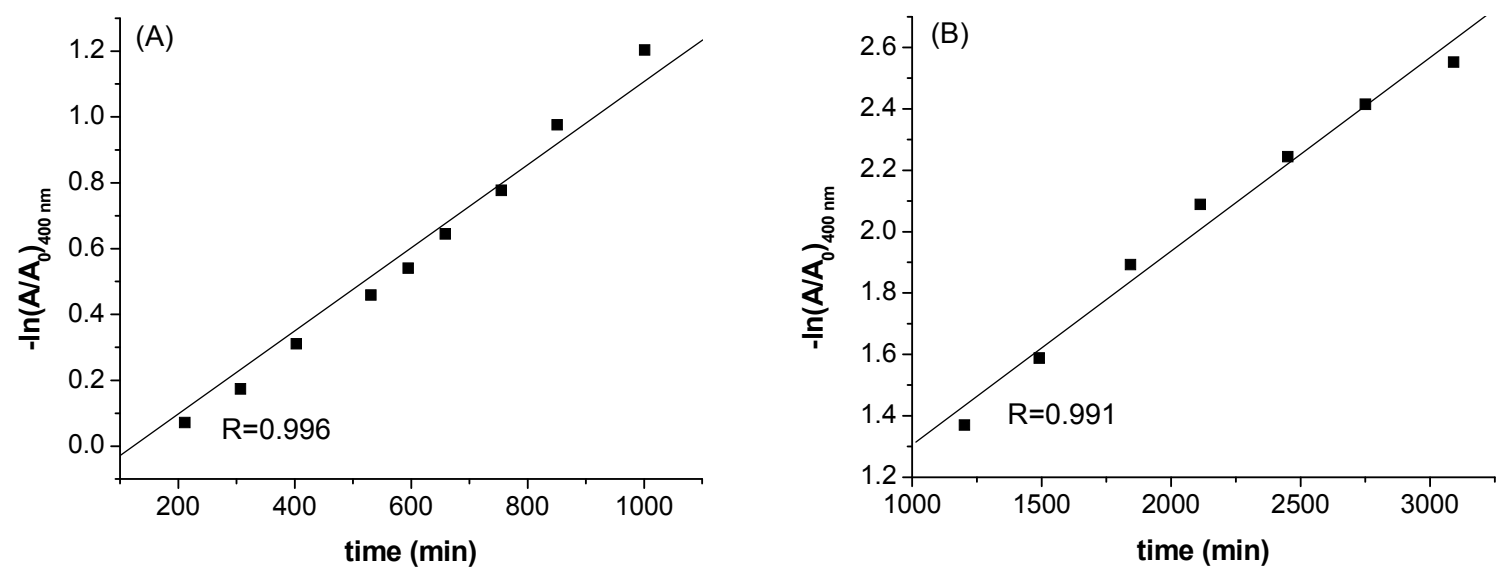

Fig 3 - The plot of $\ln \left(\mathrm{A} / \mathrm{A}_{0}\right)$ as a function of the reaction time for the first $(\mathrm{A})$ and second $(\mathrm{B})$ domains; $\mathrm{A}_{0}$ and A denote the absorbance of 4-nitrophenol at time $t=0$ and at a time $t$, respectively.

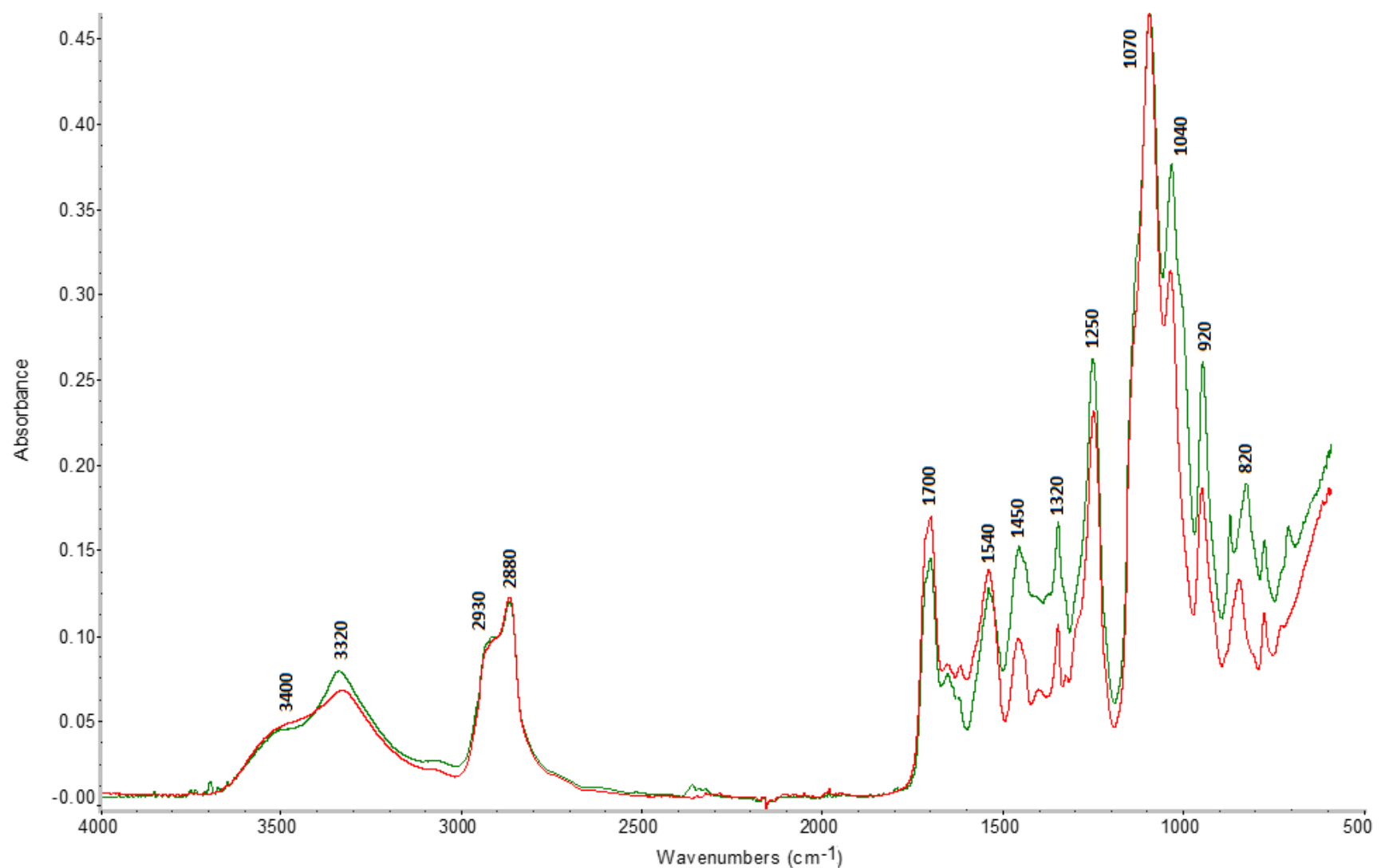

Fig. 4 - Infrared spectra of the PEG900/ $/$-CD hydrogel/AuNPs hybrid material before (green) and after (red) reduction of 4-nitrophenol.

In order to determine whether the integrity of the PEG900//-CD hydrogel/AuNPs hybrid material was affected by the reduction process, the infrared spectra of the wet material were recorded before and after reduction. No significant changes are observed, as revealed by the spectra shown in Fig. 4. Both spectra present the characteristic vibrational bands of PEG $900^{23}$ at $2880 \mathrm{~cm}^{-1}\left(\mathrm{CH}_{2}\right.$ stretching), $1450 / 1320 \mathrm{~cm}^{-1} \quad(\mathrm{C}-\mathrm{H} \quad$ bending/ scissoring) and $1250 \mathrm{~cm}^{-1}$ (C-O-C stretching), and of $\beta-\mathrm{CD}^{24}$ at $3400-3300 \mathrm{~cm}^{-1}$ (O-H stretching), $2930 \mathrm{~cm}^{-1}$ (CH and $\mathrm{CH}_{2}$ stretching) and $1040 \mathrm{~cm}^{-1}$ (O-H bending). The peak at $1700 \mathrm{~cm}^{-1}$ arises from $\mathrm{H}-\mathrm{O}-\mathrm{H}$ deformations of water molecules present in the $\beta$-CD cavity. ${ }^{25}$ Moreover, the reduction process was repeated and it was observed that the catalytic activity of the encapsulated AuNPs was preserved for a second catalytic cycle. 


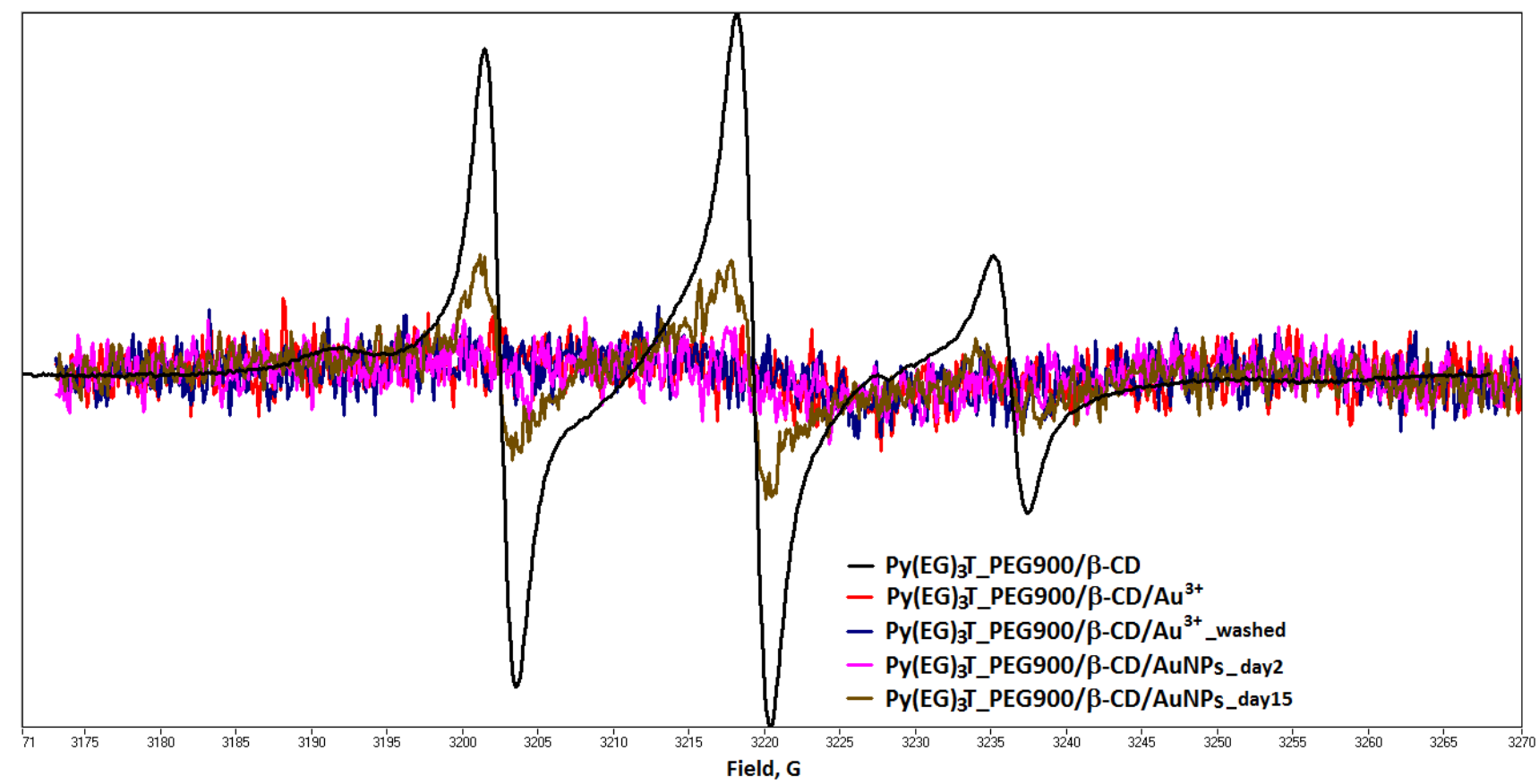

Fig. 5 - The EPR spectra of the Py(EG) $)_{3}$ T dual probe in PEG900/ $\beta$-CD hydrogel, prior to and after AuNPs formation within gel.

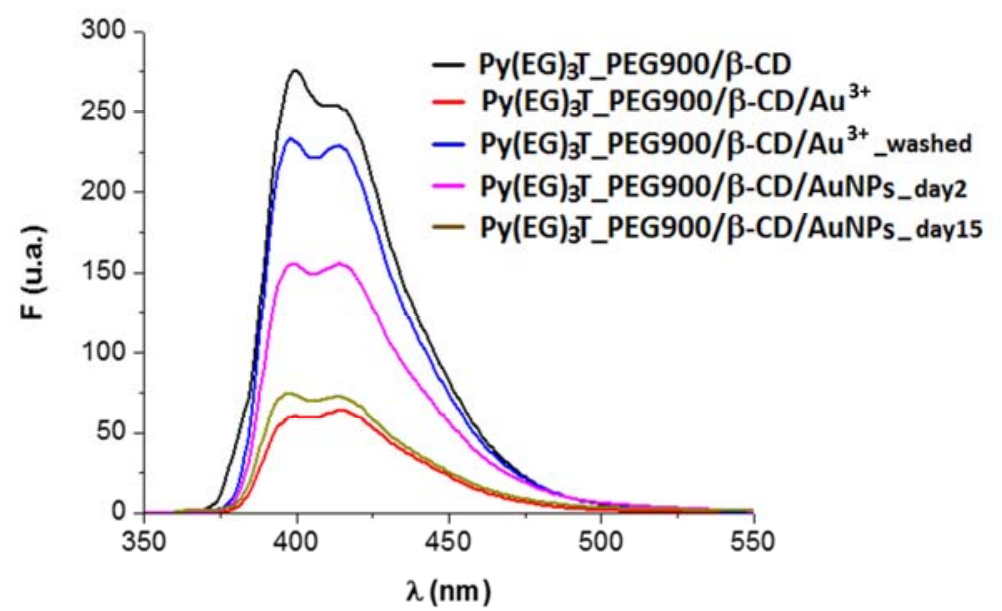

Fig. 6 - Fluorescence spectra of the Py(EG) $)_{3}$ T dual probe in PEG900/ $\beta-C D$ hydrogel, prior to and after AuNPs formation within the gel.

\section{Reduction of nitroxide at the surface of AuNPs encapsulated in PEG900/ק-CD hydrogel}

After confirming the catalytic activity of AuNPs encapsulated in PEG900/ $\beta$-CD hydrogel, we investigated the spectral behaviour of a dual molecular probe, denoted $\mathrm{Py}(\mathrm{EG})_{3} \mathrm{~T}$ (Fig. 1), in the PEG900/ $\beta$-CD hydrogel prior to and after AuNPs formation within the gel. The probe bears a fluorescent pyrene moiety, Py connected to a TEMPO paramagnetic moiety, T via a triethylene glycol linker, $(E G)_{3}$.

In Fig. 5, the black spectrum corresponds to the electron paramagnetic resonance (EPR) signal of the $\mathrm{Py}(\mathrm{EG})_{3} \mathrm{~T}$ dual probe in $\mathrm{PEG} 900 / \beta-\mathrm{CD}$ hydrogel. The analysis of the EPR spectra of $\operatorname{Py}(E G)_{3} T$ in solution and in PEG900/ $\beta-C D$ hydrogel has been described previously. ${ }^{16}$ This molecular probe has a slower dynamic within gel compartments due to interactions with $\beta-\mathrm{CD}$ cavities and gel fibres. This is revealed by a broadening of the EPR lines of the probe in gel as compared to the probe in solution. After diffusion of the $A u(I I I)$ ions but prior to the formation of AuNPs, the medium is acidic, therefore the reduction of the nitroxide group occurs rapidly, as observed by the disappearance of the EPR signal (Fig. 5, red and blue spectra). Since the quenching effect of the nitroxide moiety on the fluorescence intensity of the pyrene group has been previously 
documented, ${ }^{16,26}$ one would expect the fluorescence intensity of the dual probe to increase following nitroxide reduction. However, this effect is not observed in the fluorescence spectrum (Fig. 6 , black vs. red spectra) due to the quenching of pyrene emission by $\mathrm{Au}(\mathrm{III})$ ions. ${ }^{27}$ Washing the gel removed the excess of $\mathrm{Au}(\mathrm{III})$ ions and an increase in the fluorescence emission was indeed recorded (Fig. 6, blue spectrum). The formation of AuNPs determines a decrease of the fluorescence intensity (Fig. 6, magenta and brown spectra). Conversely, the EPR signal of the dual probe is partially restored in time (Fig. 5, magenta and brown spectra), which indicates the oxidation of hydroxylamine to nitroxide occurring at the surface of the encapsulated AuNPs.

\section{EXPERIMENTAL}

\section{Materials}

$\mathrm{HAuCl}_{4}, \mathrm{NaBH}_{4}$ and 4-nitrophenol were purchased from Sigma-Aldrich. $\mathrm{NaOH}$ was purchased from Lach-Ner. The PEG900/ $\beta$-CD hydrogel was prepared following the protocol reported in ref. ${ }^{17,28,29}$. The PEG900/ $\beta$-CD hydrogel/AuNPs hybrid material was obtained as reported previously. ${ }^{15}$ The dual molecular probe $\mathrm{Py}(\mathrm{EG})_{3} \mathrm{~T}$ was synthesized following the procedure from ref. ${ }^{16}$

\section{Sample preparation and instruments}

The EPR spectra were recorded on a JEOL FA 100 spectrometer equipped with a cylindrical type resonator TE011, operating at a frequency modulation of $100 \mathrm{kHz}$, microwave power of $0.998 \mathrm{~mW}$, sweep time of $480 \mathrm{~s}$, modulation amplitude of $1 \mathrm{G}$, time constant of $0.3 \mathrm{~s}$ and a magnetic field scan range of $100 \mathrm{G}$.

The UV-Vis absorption spectra were recorded on an UVD-3500 double beam spectrophotometer. A solution containing 4-nitrophenol $\left(6 \times 10^{-5} \mathrm{M}\right.$ in $\left.0.1 \mathrm{M} \mathrm{NaOH}\right)$ and $\mathrm{NaBH}_{4}(0.2 \mathrm{M})$ was placed in contact to the PEG900/3-CD hydrogel/AuNPs hybrid material, and the absorption spectrum of the solution was recorded at different time intervals.

Steady-state fluorescence spectra were recorded on a JASCO FP-6500 spectrofluorometer equipped with an accessory for solid sample measurements. The excitation wavelength was set at $340 \mathrm{~nm}$.

FTIR spectra of gels were recorded on a Thermo Scientific Nicolet iS10 FT-IR spectrometer.

\section{CONCLUSIONS}

In summary, in this study we explored the catalytic activity of AuNPs embedded in a PEG900/ $\beta$-CD hydrogel matrix towards the 4nitrophenol reduction reaction, and we monitor the spectral changes of a fluorescent-paramagnetic dual molecular probe during the formation of
AuNPs in PEG900/ $\beta$-CD hydrogel. The structural integrity of the material was confirmed by infrared spectroscopy and its catalytic activity was preserved for a second catalytic cycle.

Acknowledgements. This work was supported by a grant from the Roumanian National Authority for Scientific Research, CNCS-UEFISCDI, project number PN-III-P4IDPCE-2016-0734, and carried out within the research direction "EPR and fluorescence studies on supramolecular interactions in inhomogeneous systems" of the "Ilie Murgulescu" Institute of Physical Chemistry.

\section{REFERENCES}

1. A. Corma and H. Garcia, Chem. Soc. Rev., 2008, 37, 2096-2126.

2. E. Faoucher, P. Nativo, K. Black, J. B. Claridge, M. Gass, S. Romani, A. L. Bleloch and M. Brust, Chem. Commun., 2009, 6661-6663.

3. M. Conte, H. Miyamura, S. Kobayashi and V. Chechik, J. Am. Chem. Soc., 2009, 131, 7189-7196.

4. P. Ionita, A. Caragheorgheopol, B. C. Gilbert and V. Chechik, Langmuir, 2004, 20, 11536-11544.

5. P. Ionita, M. Conte, B. C. Gilbert and V. Chechik, Org. Biomol.Chem., 2007, 5, 3504-3509.

6. B. Marchetti, Y. Joseph and H. Bertagnolli, J. Nanopart. Res., 2011, 13, 3353-3362.

7. M. Haruta, Gold Bull., 2004, 37, 27-36.

8. J. Li, C. Liu and Y. Liu, J. Mater. Chem., 2012, 22, 84268430.

9. D. Astruc, F. Lu and J. R. Aranzaes, Angew. Chem., Int. Ed., 2005, 44, 7852-7872.

10. P. Botella, A. Corma and M. T. Navarro, Chem. Mater., 2007, 19, 1979-1983.

11. G. Liu, X. Hong and S. C. E. Tsang, New J. Chem., 2013, 37, 2969-2972.

12. M. Kimura, S. Kobayashi, T. Kuroda, K. Hanabusa and H. Shirai, Adv. Mater., 2004, 16, 335-338.

13. P. K. Vemula and G. John, Chem. Commun., 2006, 22182220.

14. B. O. Okesola, S. K. Suravaram, A. Parkin and D. K. Smith, Angew. Chem. Int. Ed., 2016, 55, 183-187.

15. G. Ionita, G. Marinescu, C. Ilie, D. F. Anghel, D. K. Smith and V. Chechik, Langmuir, 2013, 29, 9173-9178.

16. S. Mocanu, I. Matei, S. Ionescu, V. Tecuceanu, G. Marinescu, P. Ionita, D. Culita, A. Leonties and G. Ionita, Phys. Chem. Chem. Phys., 2017, 19, 27839-27847.

17. G. Ionita, A. M. Ariciu, I. M. Turcu and V. Chechik, Soft Matter, 2014, 10, 1778-1783.

18. S. Wunder, Y. Lu, M. Albrecht and M. Ballauff, ACS Catal., 2011, 1, 908-916.

19. P. Herves, M. Perez-Lorenzo, L. M. Liz-Marzan, J. Dzubiella, Y. Lub and M. Ballauff, Chem. Soc. Rev., 2012, 41, 5577-5587.

20. C. Deraedt, L. Salmon, S. Gatard, R. Ciganda, R. Hernandez, J. Ruiz and D. Astruc, Chem. Commun., 2014, 50, 14194-14196.

21. T. Ma, W. Yang, S. Liu, H. Zhang and F. Liang, Catalysts, 2017, 7, 38.

22. H. Wang, Y. Shi, M. Haruta and J. Huang, Appl. Catal. A Gen., 2017, 536, 27-34. 
23. S. Pramanik, F. Ataollahi, B. Pingguan-Murphy, A. Ataollahi Oshkour and N. A. Abu Osman, Sci. Rep., 2015, 5, 9806.

24. K. P. Sambasevam, S. Mohamad, N. Muhamad Sarih and N. Atiqah Ismail, Int. J. Mol. Sci., 2013, 14, 3671-3682.

25. H. Rachmawati, C. A. Edityaningrum and R. Mauludin, AAPS PharmSciTech, 2013, 14, 1303-1312.
26. G. I. Likhtenstein, K. Ishii and S. Nakatsuji, Photochem. Photobiol., 2007, 83, 871-881.

27. Z. Song, C. Xiao, Y. Dai, Q. Fei, Y. Huan and G. Feng, Nanotechnology, 2012, 23, 425501.

28. G. Ionita and V. Chechik, Chem. Commun., 2010, 46, $8255-8257$.

29. L. C. Cesteros, C. A. Ramirez, A. Pecina and I. Katime, Macromol. Chem. Phys., 2007, 208, 1764-1772. 
